\title{
Effect of Different Dance Training on Vital Capacity among Post-Pubescent Girls
}

\author{
Sabaananth. $S^{1}$,Gopinath. $V^{2}$, Thevanthy. $T^{3}$ \\ ${ }^{1}$ Sports Science Unit, University of Jaffna, Sri Lanka \\ ${ }^{2}$ Department of Physical Education and Sports Sciences Annamalai University, Chidambaram, India \\ ${ }^{3}$ Department of Dance, RAFA, University of Jaffna, Sri Lanka
}

\begin{abstract}
The pulmonary and circulatory system are responsible for sending blood to lungs and returned to the heart and getting rid of waste products in your blood while helping to distribute blood rich in oxygen. Dance training can help to strengthen and make this system more efficient. The aim of this study was to investigate the effect of different dance training on Forced Vital Capacity. To achieve the purpose ninety $(N=90)$ women students (mean age 17 years) were randomly selected from, Jaffna, Sri Lanka as subjects and divided in to Aerobic Dance ( $A D)$, Bharathanatyam Dance (BD) and Kandyan Dance KD) groups. They practice their respective dance for $60 \pm 10 \mathrm{~min} /$ day for 3 days / a week over the period of twelve weeks. Data were collected on Forced Vital Capacity (FVC) by PC based USB Spirometer before and after the intervention programme. Dependent ' $t$ ' test was used to find out difference between pre and post test. After eliminating the influence of pre-test on post-test means of experimental groups the analysis of variance (ANOVA) was used to find out the mean gain differences. In addition to this, Scheffe's post-hoc test was employed $(p=0.05)$. The results of the study reveal, aerobic (Percentage of Improvement (PI) 48.16), bharathanatyam (PI 37.56), kandyan (PI 32) dance training influenced the forced vital capacity. Further the result of post hoc test shows that there was a significant difference between Aerobic and Bharathanatyam (Mean Gain Difference (MGD) 0.28*), Aerobic and Kandyan dance (MGD $\left.0.41^{*}\right)$ groups on Forced Vital Capacity. However in Bharathanatyam dance and Kandyan dance (MGD 0.13) a insignificant difference was observed on vital capacity. From the result it was concluded that Aerobic, Bharathanatyam and Kandyan dance training positively influence on pulmonary function in respect of forced vital capacity.
\end{abstract}

KEYWORDS: Bharathanatyam, Aerobic, Kandyan Dance, FVC. 


\section{INTRODUCTION}

The cardiorespiratory system is responsible for sending blood to lungs and back to the heart and getting rid of waste products in your blood while helping to distribute blood rich in oxygen. Exercise can help strengthen and make this system more efficient. Pulmonary functions are generally determined by respiratory muscle strength, compliance of the lung and thoracic cavity, airway resistance and elastic recoil of the lungs ${ }^{1}$. Long-term exercise can help to make the muscles that expand the lungs stronger and more efficient. This can increase the amount of expansion of the chest to breathe in more air with each breath and increase thenumber of capillaries around the alveoli, or air sacs, enabling to absorb oxygen in the blood quicker. This results in being able to exercise at a higher intensity for a longer period of time.

It is acknowledged that low physical activity and fitness levels are associated with ill health. $^{2-5}$ Although, there is evidence that exercise can be of benefit to health, it must be regular, if these benefits are to be attained/maintained. Thus, it is important that regular physical activity is encouraged and that appropriate exercise sessions are promoted. However, the mode of exercise must be acceptable to the target population that is, the participants must find the activity enjoyable and be able to participate regularly and it may be necessary to show that the exercise prescription is effective in improving fitness levels. Dance may also be regarded as a form of nonverbal communication between humans. ${ }^{6}$ Dance involves the body, emotion and mind: it is both a physical activity and a means of expression and communication. Gymnastics, figure skating and synchronized swimming are sports that incorporate dance, while martial arts kata are often compared to dances. Dance may also be regarded as a form of nonverbal communication between humans. Motion in ordinarily inanimate objects may also be described as dances (the leaves danced in the wind). ${ }^{7}$

The physiological response to dance is dependent on the intensity, duration and frequency of the exercise as well as the environmental conditions. During dance practice, requirements for oxygen and substrate in skeletal muscle are increased, as are the removal of metabolites and carbon dioxide. Chemical, mechanical and thermal stimuli affect alterations in metabolic, cardiovascular and ventilator function in order to meet these increased demands. A good dancer must also possess great coordination, highly developed kinesthetic awareness and control balance in motion. Endurance is essential to continue prolonged dance performance to develop awareness of space, a strong sense of rhythm, and an appreciation of music. Particularly in theatrical dance, the dancer must be able to project movement clearly and make its expressive qualities intelligible to the audience. Grace, fluidity, and the harmony of the body are also frequently desired in the dancer, as is physical beauty. ${ }^{8}$

Aerobic dance: In the early 70's, Jacki Sorenson developed a fitness program now known as aerobic dance, which was designed to improve cardiovascular endurance. It involves choreographed routines made up from various dance steps and other movements including walking, running and skipping. It also involves muscle conditioning exercises for the abdominal, legs and arms. ${ }^{9}$ Aerobic dance is appropriate for the general public since skill and technique are not emphasized.$^{10}$ Bharatanatyam: very popular and oldest of all 
classical dance forms. The general etymology of Bharathanatyam is BHAva (expression) + RAga (music) + TAla(rhythm) + NATYAM(dance). ${ }^{11}$ The variety style of the dance and musical accompaniment provide the people with tastes in performing them. Kandyan Dance: is a dance form that originated in an area called Kandy of the Central region of Sri Lanka. But today it has been widespread to other parts of the country. ${ }^{12}$ The dance waned in popularity as the support for the dancers from the Kandyan kings ended during the British period. It has now been revived and adapted for the stage and is Sri Lanka's primary cultural export. ${ }^{13}$ Forced vital capacity is the maximal volume of gas that can be expelled from the lungs by forceful effort following a maximal inspiration. ${ }^{14}$ Hence the purpose of the study was to find out the effect of different dance training on forced vital capacity among post pubescent girls.

\section{MAERIALS AND METHODS}

To achieve the purpose ninety ( $\mathrm{N}=90)$ women students (mean age $17 \pm 1.3$ years) were randomly selected from, Jaffna, Sri Lanka as subjects and divided in to Aerobic Dance (AD), Bharathanatyam Dance (BD) and Kandyan Dance (KD) groups. They practiced their respective dance for $60 \pm 10 \mathrm{~min} /$ day for 3 days / week over the period of twelve weeks. Data were collected on Forced Vital Capacity (FVC) by PC based USB Spirometer before and after the intervention programme. Dependent ' $t$ ' test was used to find out the difference between pre and post test. After eliminating the influence of pre-test on post-test means of experimental groups the analysis of variance (ANOVA) was used to find out the mean gain differences. In addition to this, Scheffe's post-hoc test was employed $(\mathrm{p}=0.05)$.

\section{RESULTS}

Effect of different dance training on vital capacity among post pubescent girls.

\begin{tabular}{|c|c|c|c|c|c|}
\hline 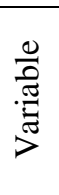 & Group & 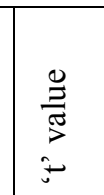 & $\begin{array}{l}\text { Magnitude } \\
\text { of } \\
\text { improveme } \\
\text { nt in } \%\end{array}$ & 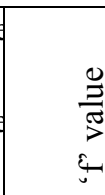 & CI \\
\hline \multirow{3}{*}{ VC } & $\mathrm{AD}$ & $21.32 *$ & 46.16 & \multirow{3}{*}{$8.18 *$} & \multirow{3}{*}{0.25} \\
\hline & BD & $\begin{array}{c}8.88 \\
*\end{array}$ & 37.56 & & \\
\hline & KD & $\begin{array}{c}7.77 \\
*\end{array}$ & 32 & & \\
\hline
\end{tabular}

*Significant at .05 level of confidence. with df (2, 29 ) is 2.04 , TV : $0.05 \mathrm{df} 2$ and $87=3.10$

The result of the study on vital capacity indicates that there was significance difference between pre and post test among the Aerobic, Bharathanatyam and Kandyan Dancers. Further the result of post hoc test shows that there was a significant difference between Aerobic and Bharathanatyam (Mean Gain Difference (MGD) 0.28*), Aerobic and Kandyan dance (MGD $0.41^{*}$ ) groups on Forced Vital Capacity. An insignificant difference was observed between Bharathanatyam dance and Kandyan Dance (MGD 0.13) insignificant difference on vital capacity.

\section{DISCUSSION}

Inactivity and low cardio-respiratory fitness are recognized as important causes of morbidity and mortality. ${ }^{15,16}$ It is generally accepted that people with higher levels of physical activity tend to have higher levels of fitness and that physical activity can improve cardio respiratory fitness. ${ }^{17}$ Dance is a predominantly intermittent type of exercise. In choreographed dance training is demanding and is a form of energetic 
physical movement. In the present study, FVC increased significantly in the experimental groups after twelve weeks of dance training. Other studies comparing respiratory function among men and women engaged in various sports found that sports person have higher level of pulmonary function than sedentary people. ${ }^{18}$ Our result correlates with Y.J. Cheng et al, Who showed in their study that physical activity improved pulmonary function in healthy sedentary people. ${ }^{19}$ Our study also corresponds with Reza Farid et al. Who have showed improvement in pulmonary function with aerobic type exercise in asthma patients. ${ }^{20}$ Cedric Nourrey et al Showed in a prospective study, aerobic exercise improves pulmonary function and alters exercise breathing patterns in children. ${ }^{21}$ K.D. Bruce G Nickerson et al have shown their study that distance running programmes improved fitness in asthmatic children or changes in exercise induced bronchospasm. ${ }^{22}$ C.J Clark found that cardiorespiratory fitness significantly improved and breathlessness decreased over a wide range of work corresponding to activities of healthy people; and thus provides further support for the dance training being an important component of pulmonary rehabilitation. ${ }^{23}$ Present study also correlates with the above findings and showed that the experimental groups were able have more powerful and more effective expiration as opposed to what they had been before.

\section{CONCLUSION}

Hence it may be concluded that, Aerobic Bharathanatyam and Kandyan dances are effective methods to improved pulmonary function in respect of vital capacity for female dancers.

\section{IMPLICATION}

In brightness of these studies and with enlarged understanding of the artists there is a need to prepare physiologically to tolerate extreme theater demands.

\section{REFERENCE}

COTES JE. (1975). Lung function assessment and application in Medicine. 3rd ed. Oxford: Blackwell Scientific publications.

BLAIR SN, KOHL HW, (1989). Paffenbarger RS,et al. Physical fitness and all-cause mortality. A prospective study of healthy men and women. JAMA;262:2395-401.

DARGIE HJ, GRANT S. (1991). Exercise.BMJ;303:910-13.

BLAIR S, CONNELLY J. (1994). How much physical activity should we do? The case for moderate amounts and intensities of physical activity. The Health of the Nation. 22:1-13.

BOUCHARD CR, SHEPHARD R, STEPHENS

T. (1994). Physical activity, fitness and health: international proceedings and consensus statement. Champaign,IL: Human Kinetics.http://en.wikipedia.org/wiki/Dance.

JAYNE C.BERNASCONI, NANCY E. SMITH. (2008). Aerial Dance. Human Kinetics; 1 edition. Pp 14.

http://www.academicroom.com/topics/whatis-dance.

BLYTH, M., \& GOSLIN, B.R. (1985). Cardiorespiratory responses to "aerobic dance". Journal of Sports Medicine, 25, 5764.

PERRY, A., MOSHER, P., LAPERRIÈRE, A., ROALSTAD, M., " OSTROVSKY, P. (1988). A comparison of training responses to interval versus continuous aerobic dance. The Journal of sports Medicine and Physical Fi tness, $\quad \sim 8, \quad 274-279$. 
http://natyanjali.blogspot.com/2008/08/bhara tnatyamthe-first-indian-classical.html http://amadanceacademy.com.au/?page_id=1 $\underline{8}$

http://en.wikipedia.org/wiki/Kandyan_dance HERBERT A. DEVRIES., TERRY J. HOUSH (1994). Physiology of Exercise for Physical Education, Athletics and Exercise Science. Fifth Edition. P. 140.

U.S. DEPARTMENT OF HEALTH AND HUMAN SERVICES. (1996). Physical Activity and Health: A Report of the Surgeon General. Atlanta, GA: Department Of Health And Human Services, Centers for Diease Control and Prevention, National Center for Chronic Disease Prevention and Health Promotion,

TWISK JW,STAAL BJ,BRINKMAN MN,ET AL.(1998). Tracking of lung function parameters and the longitudinal relationship with lifestyle. Eur Respir J1998;12: 627-34.

CECIL M. BURCHFIEL, PAUL L. ENRIGHT, DAN S. SHARP, ET AL. (1997). Factors associated with variations in pulmonary functions among elderly japanese- american men. Chest1997;112:87-97

MEHROTRA PK, VARMA N, TIWARI S. (1998). Pulmonary Function In Indian Sportsmen Playing Different Sports. Indian Journal of Physiology and Pharmacology. 42:412-16.

Y.J. CHENG, C A MACERA, C L ADDY, ET AL. (2003). Effects of physical activity on exercise tests and respiratory func-tion.Br. J. Sports Med.2003;37:521-528.

REZA FARID, FARAHZAD JABBARI AZAD, AHMAD EBRAHIMI ATRI, ETAL.(2005). Effect of aerobic exercise training on pulmonary function and tolerance of activity in asthmatic patients.Iran $\mathbf{J}$ Allergy Asthma Immunol 2005; 4(3): 13338.
NOURRY C,DERUELLE F,GUINHOUYA C, ET AL. (2005). High intensity running training improves pulmonary function andalters exercise breathing pattern in children. Eur J Appl.Physiology 2005; 94(4): 415-423.

BRUCE G. NICKERSON, DAISY B. BAUTISTA, MARLA A. NA-MEY, ETAL.(1983). Distance running improves fitness in asthmatic children without pulmonary complications or changes in exercise induced bronchospasm. Pediatrics1983;71(2):147-152.

C.J.CLARK. (1992). THE ROLE OF PHYSICAL TRAINING IN ASTHMA. CHEST1992;101(5): 293S-298S 